\title{
Three-dimensional $P$ and $S$ wave velocity structures beneath the Hokkaido corner, Japan-Kurile arc-arc junction
}

\author{
Kei Katsumata, Naoto Wada, and Minoru Kasahara \\ Institute of Seismology and Volcanology, Hokkaido University, Sapporo 060-0810, Japan \\ (Received May 12, 2006; Revised June 30, 2006; Accepted July 18, 2006; Online published September 15, 2006)
}

\begin{abstract}
We applied an inverse method developed by Zhao et al. (J. Geophys. Res., 97, 19909-19928, 1992) to 42,834 $P$ and 18,263 $S$ wave arrival time data observed at 152 seismographic stations for 1143 local earthquakes at depths between 0 and $200 \mathrm{~km}$ in order to estimate three-dimensional $P$ and $S$ wave velocity structures beneath the Hokkaido corner, Japan-Kurile arc-arc junction. High- and low-velocity zones were clearly imaged in the Hidaka Mountain Range at depths shallower than $35 \mathrm{~km}$. The low-velocity anomalies of $P$ and $S$ waves were found to be distributed in the mantle wedge at depths between 35 and $100 \mathrm{~km}$ beneath the volcanic front, as also observed in the Tohoku region. Another low-velocity zone was found to exist in the fore-arc region at depths of 50-70 km above the plate boundary; this zone was not detected in Tohoku, suggesting that the dehydration process in the fore-arc region is different from that in the Tohoku region.
\end{abstract}

Key words: Hokkaido, $P$ and $S$ wave velocity structures, Hidaka Mountain Range, volcanic front, mantle wedge, magma, dehydration process.

\section{Introduction}

The velocity structure of seismic waves is one of the most important physical parameters used to investigate heterogeneities in the crust and the mantle of the earth. A number of researchers have studied three-dimensional (3D) $P$ and $S$ wave velocity structures beneath the Hokkaido corner, Japan-Kurile arc-arc junction (Takanami, 1982; Miyamachi and Moriya, 1984; Miyamachi et al., 1994; Murai et al., 2003; Ogiso et al., 2005) (Fig. 1). The Pacific plate at the northwestern part of the Pacific Ocean is descending beneath the Kurile Islands and Japan Islands. The northern part of Honshu, Hokkaido and Kurile Islands is located on the North American plate or on the Okhotsk plate (see Takahashi et al., 1999). According to the NUVEL-1A model the Pacific plate around the Hokkaido corner moves in a $\mathrm{N} 63^{\circ} \mathrm{W}$ direction at a speed of $83 \mathrm{~mm} /$ year relative to the North American plate (DeMets et al., 1994).

There is yet another plate-like motion in the Hokkaido corner. The Kurile Islands arc is moving toward the southwest at a speed of 6-11 mm/year relative to the North American plate (DeMets, 1992) and has been colliding against the northeastern Japan arc since middle Miocene, forming the arc-arc type Hidaka collision zone (HCZ) in and around the Hokkaido corner (see Kimura, 1996). The results of seismic reflection surveys suggest that the lower crust of the Kurile Islands arc was delaminated at the HCZ by this collision (Tsumura et al., 1999). The Hidaka Mountain Range (HMR) located at the HCZ is uplifting as a result of these processes.

The purpose of this study is to obtain a more detailed 3D

Copy right(c) The Society of Geomagnetism and Earth, Planetary and Space Sciences (SGEPSS); The Seismological Society of Japan; The Volcanological Society of Japan; The Geodetic Society of Japan; The Japanese Society for Planetary Sciences; TERRAPUB. picture of the $P$ and $S$ wave velocity structures in this wide area, including the volcanic front, with a spatial resolution smaller than $50 \mathrm{~km}$ by using travel time data from a new dense seismographic network.

\section{Data and Method}

We used waveform data from 47 temporary seismographic stations in and around the HMR that were deployed in July 1999 and retrieved in June 2001 (Fig. 1). Each station consisted of a short-period three-component seismometer with a natural frequency of $1 \mathrm{~Hz}$. All waveform data were telemetered by way of a communication satellite. We also used waveform data from stationary seismic stations in Hokkaido and northeastern Japan islands. They are maintained by Institute of Seismology and Volcanology, Hokkaido University (ISV), Japan Meteorological Agency (JMA), Tohoku University, Hirosaki University and National Research Institute for Earth Science and Disaster Prevention (NIED). The high sensitivity seismograph network (Hi-net) is constructed and maintained by NIED and has been functional in Hokkaido since October 2000. We downloaded waveform data of earthquakes larger than $M=3.5$ from the website of NIED up until the end of our short-term observational period.

For a seismic tomography method to be reliable, a vast number of accurate and reliable arrival time data are needed. One of the authors examined all waveform data one by one alone and, after a careful inspection, selected 42,834 $P$ wave and 18,268 $S$ wave arrival times from 1143 earthquakes. Among the selected earthquakes 99 occurred at depths of less than $15 \mathrm{~km}, 117$, at depths between 15 and $30 \mathrm{~km}, 300$ at depths between 30 and $60 \mathrm{~km}, 277$ at depths between 60 and $100 \mathrm{~km}$ and 335 at depths between 100 and $200 \mathrm{~km}$; 15 occurred deeper than $200 \mathrm{~km}$. Around the HMR 


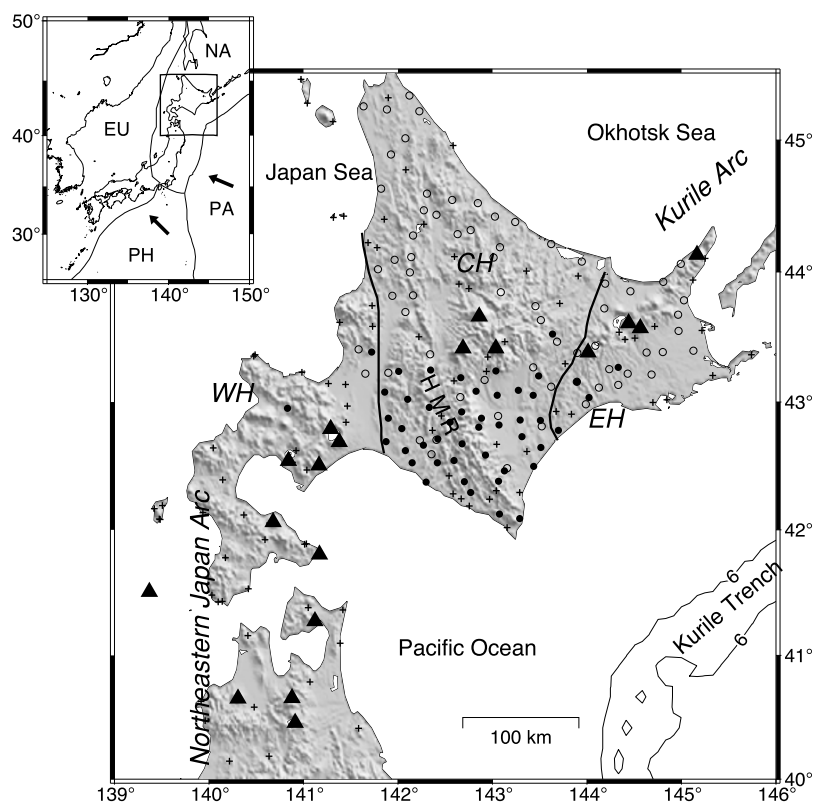

Fig. 1. Tectonic map of the Hokkaido corner region. Triangles are active volcanoes. Bold lines are tectonic lines dividing Hokkaido Island into three regions: Western Hokkaido (WH), Central Hokkaido $(\mathrm{CH})$ and Eastern Hokkaido (EH). HMR indicates the Hidaka Mountain Range. Closed circles, crosses and open circles indicate the temporary seismographic stations from 1999 to 2001, the stationary stations and the Hi-net stations, respectively. The inset shows plate boundaries: the Eurasian (EU), the Pacific (PA), the North American and the Philippine Sea $(\mathrm{PH})$ plates.

the seismic activity is very high down to the upper mantle due to the collision between the Kurile Islands arc and the northeastern Japan arc. A seismic zone associated with the subducting Pacific plate is getting deep in the north or northwest directions. All selected earthquakes had ten or more $P$ wave readings. The accuracy for most $P$ and $S$ arrival times are considered to be $0.05-0.1 \mathrm{~s}$ and $0.1-0.2 \mathrm{~s}$, respectively.

Zhao et al. (1992) and Zhao and Hasegawa (1993) developed an improved tomographic method to study the deep structure of the Japan subduction zone. We have applied the same tomographic method in order to obtain 3D $P$ and $S$ wave velocity structures in the Hokkaido corner region. The study area $\left(40.75-44.25^{\circ} \mathrm{N}, 140.75-145.25^{\circ} \mathrm{E}\right)$ was divided into grids with spacing $0.25^{\circ}$ in longitude $\times 0.25^{\circ}$ in latitude on each plane at depths of 5, 20, 35, 50, 70 and 100 $\mathrm{km}$. The total number of grid nodes was 1710 . The initial $P$ wave velocities were assumed to be $6.0 \mathrm{~km} / \mathrm{s}$ at $5 \mathrm{~km}$ in depth, that is, at the upper crust; $6.7 \mathrm{~km} / \mathrm{s}$ at $20 \mathrm{~km}$, that is, at the lower crust; $7.7 \mathrm{~km} / \mathrm{s}$ at $35 \mathrm{~km}$, that is, at the most upper mantle; $7.8 \mathrm{~km} / \mathrm{s}$ at $50 \mathrm{~km} ; 7.8 \mathrm{~km} / \mathrm{s}$ at $70 \mathrm{~km} ; 7.9 \mathrm{~km} / \mathrm{s}$ at $100 \mathrm{~km}$. Zhao (1991) showed that this initial model represents well the $1 \mathrm{D}$ velocity structure for the crust and the upper mantle in Japan. The initial $S$ wave velocities were assumed to be $1 / \sqrt{3}$ of the $P$ wave velocity at each depth.

We assumed the depth distributions of the Conrad and the Moho determined by Zhao et al. (1990). The velocities increased discontinuously both at the Conrad and at the Moho. We performed the "non-plate" inversion, which was one of the tomographic methods described in Zhao et al. (1992). In this case, the depth distributions of the upper

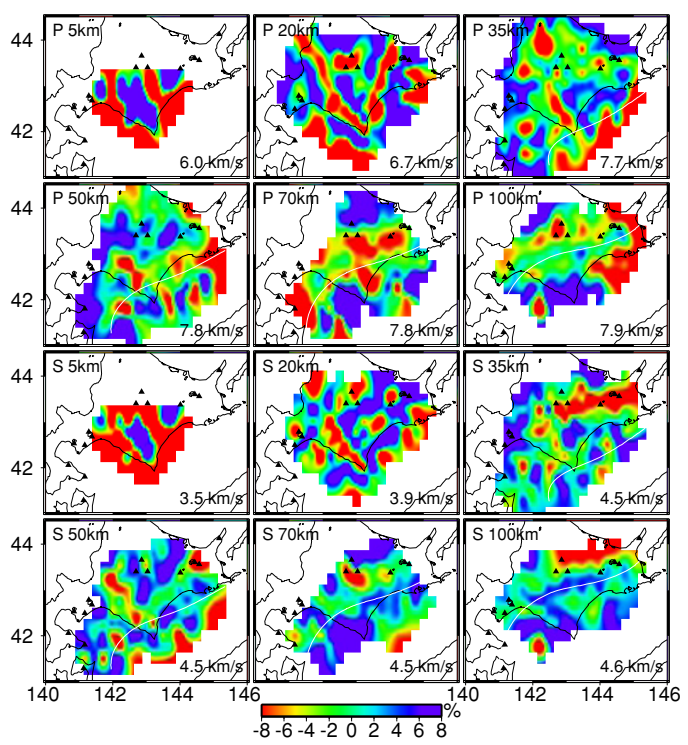

Fig. 2. $\quad P$ and $S$ wave velocity perturbations in percentages from the initial velocities. Positive and negative perturbations denote high and low velocity, respectively. The depth of the layer and the initial velocity are shown in the top left and in the bottom right corners of each map, respectively. White lines show the upper boundary of the Pacific plate at each depth determined by Katsumata et al. (2003). Triangles indicate active volcanoes.

boundary of the Pacific plate were not assumed. Although Katsumata et al. (2003) estimated the plate boundary with hypocentral distribution, we did not assume this model in our tomography. We will compare Katsumata's model with velocity structures in this study.

\section{Results}

Figure 2 shows fractional $P$ wave velocity perturbations as percentages of the initial model. Convergent solutions were obtained for $P$ waves after two iterations. We simultaneously calculated $1143 \times 4$ source parameters and 627 $P$ wave velocity perturbations for grids with 100 and more rays passing around each grid. Of these grids, $90 \%$ had 500 or more rays and $70 \%$ had 1000 or more rays. A root mean square of arrival time residuals was $0.536 \mathrm{~s}$ before the inversion, which was reduced to $0.332 \mathrm{~s}$ after two iterations; $90 \%$ of the hypocenters moved horizontally 0-7 km and vertically $0-10 \mathrm{~km}$ compared with the initial locations.

High- and low-velocity zones of $P$ waves were clearly imaged in the HMR at depths of 5,20 and $35 \mathrm{~km}$, results consistent with those obtained by Takanami (1982) and Miyamachi and Moriya (1984). The geological tectonic lines in Fig. 1 and low-velocity zones have good correlations at the depth of $20 \mathrm{~km}$. The low-velocity zone at the western foot of the HMR extends toward the northwest and runs along the tectonic line between the central and the western Hokkaido. Another low-velocity zone running around the longitude of $144^{\circ} \mathrm{E}$ corresponds to the tectonic line between central and eastern Hokkaido. Detailed explanations about these tectonic lines are provided in earlier studies (see Arita et al., 1998).

The velocity was as much as several percentage points lower at depths of 35,70 and $100 \mathrm{~km}$ beneath the volcanic front in the central and the eastern Hokkaido. However, the 


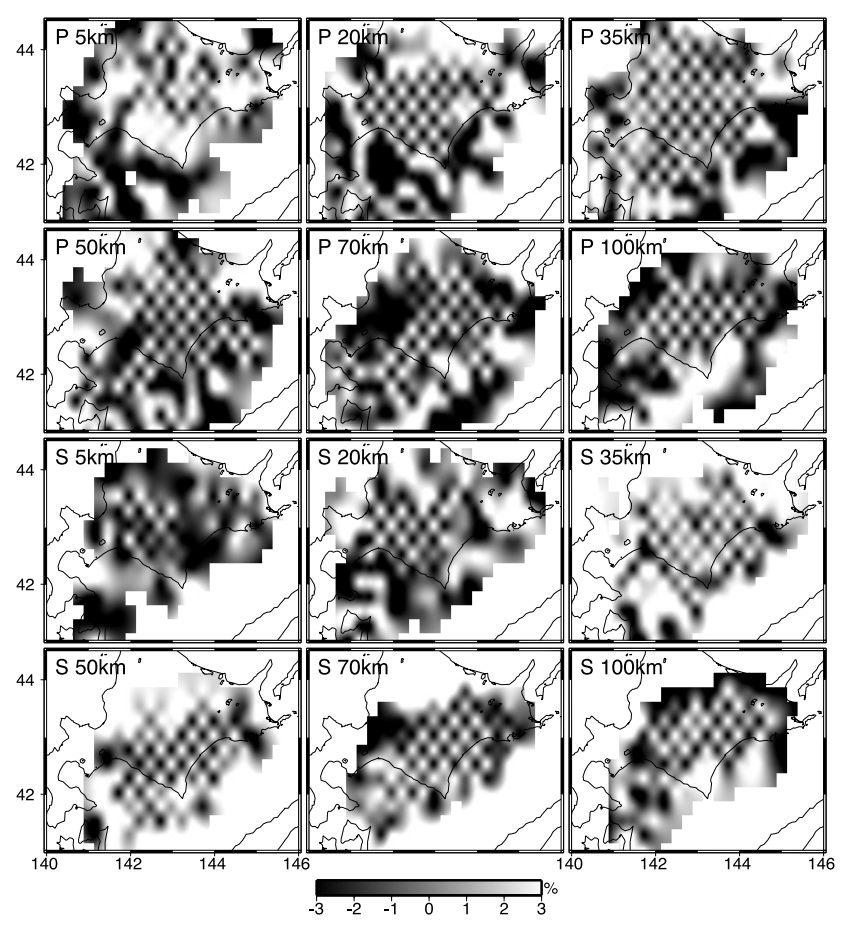

Fig. 3. Results of the checkerboard resolution test for $P$ and $S$ wave structures. The depth of the layer is shown in the top left corner of each map.

velocity was higher rather than lower at a depth of $50 \mathrm{~km}$.

Fractional $S$ wave velocity perturbations are shown as a percentage of the initial model in Fig. 2. Convergent solutions were obtained for $S$ waves after one iteration. We simultaneously calculated $1143 \times 4$ source parameters and $533 S$ wave velocity perturbations for grids with 100 and more rays passing around each grid. Of these grids, $90 \%$ had 200 and more rays and $70 \%$ had 400 and more rays. A root mean square for arrival time residual was $1.084 \mathrm{~s}$ before the inversion, which was reduced to $0.542 \mathrm{~s}$ after one iteration.

The low- and high-velocity zones beneath the HMR were also imaged by $S$ wave tomography. Low-velocity anomalies were imaged at depths of 35, 70 and $100 \mathrm{~km}$ beneath the volcanic front in the central and the eastern Hokkaido; these images are consistent with results from the $P$ wave velocity imaging. The anomaly was particularly clear at a depth 35 $\mathrm{km}$. The perturbation of $S$ wave velocity was lower than that of the $P$ wave velocity.

Figure 3 shows the results of the checkerboard resolution test for $P$ and $S$ waves. We assumed velocity perturbations of +6 and $-6 \%$ from the reference velocity at each depth. The grid size was $0.25 \times 0.25^{\circ}$. The resolution was generally high in the central part of the study area.

\section{Discussion and Concluding Remarks}

Although the study areas of Takanami (1982) and Miyamachi and Moriya (1984) were limited to around the HMR, the pattern of velocity perturbations that these two groups of researchers obtained is consistent with our results around the HMR shallower than $35 \mathrm{~km}$. A seismic refraction experiment was conducted along a profile across the study area in the investigation reported here (Research Group for Explo-
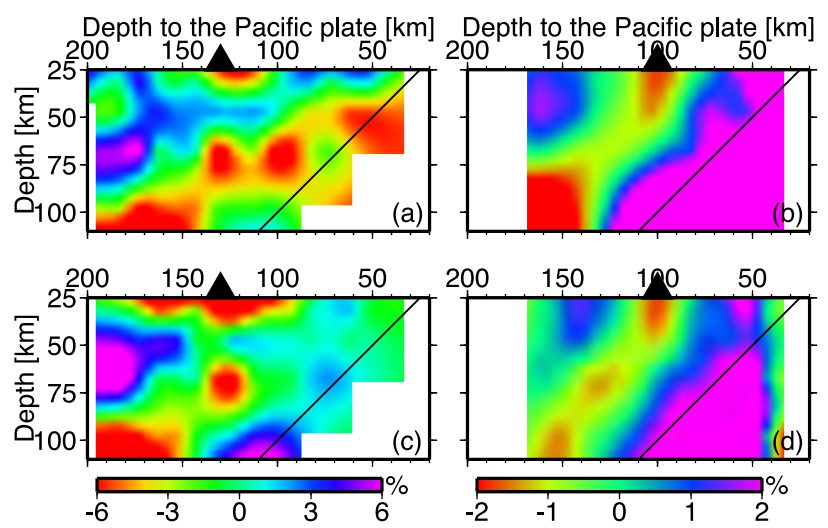

Fig. 4. Cross sections of velocity structures as a function of depth to the Pacific plate. (a) and (b) are $P$ wave in eastern Hokkaido and Tohoku, respectively. (c) and (d) are $S$ wave in eastern Hokkaido and Tohoku, respectively. Velocity perturbations were stacked up and averaged along isodepth contours of the upper boundary of the Pacific plate from $38^{\circ} \mathrm{N}$ to $40^{\circ} \mathrm{N}$ in Tohoku, from $142.5^{\circ} \mathrm{E}$ to $145^{\circ} \mathrm{E}$ in Hokkaido. Triangles and black lines indicate the volcanic front and the upper boundary of the Pacific plate, respectively. (a) and (c) used a color scale from -6 to $+6 \%$, and (b) and (d) used a color scale from -2 to $+2 \%$.

sion Seismology, 2002). Although the resolution is poor at a depth of $5 \mathrm{~km}$ in our results, the velocity perturbations are reliable since the velocity structure obtained by the seismic refraction experiment is consistent with our results. Lowvelocity areas of $P$ wave are imaged west and east of HMR at a depth of $5 \mathrm{~km}$ (Fig. 2). The seismic refraction experiment showed that sedimentary layers are very thick in these areas.

Katsumata et al. (2003) estimated the plate boundary of the Pacific plate from hypocentral distribution. Our results appear to be consistent with their model. High-velocity areas with several percent are imaged within the Pacific plate at depths of 50, 70 and $100 \mathrm{~km}$ for both $P$ and $S$ waves.

In the northeastern Japan arc (Tohoku region), the detailed $S$ wave velocity structure in the mantle wedge shows a low-velocity zone that initiates above the deep seismic zone at a depth of $140 \mathrm{~km}$, extends upward and ends at the depth of $30 \mathrm{~km}$ beneath the volcanic front (Nakajima et al., 2001, 2005). They suggested that this low-velocity zone is a pathway of the magma or fluids. In order to compare the Tohoku region with the Hokkaido corner, we made cross sections as a function of depth to the plate boundary (Fig. 4). $P$ and $S$ wave velocity perturbations were stacked up and averaged along isodepth contours of the subducted Pacific plate. In the case of Hokkaido the low-velocity zone of $S$ wave extends from $100 \mathrm{~km}$ to $30 \mathrm{~km}$, as seen in Tohoku. However the $S$ wave velocity is not so low at a depth of $50 \mathrm{~km}$ as at 35,70 and $100 \mathrm{~km}$. A high-velocity anomaly of the $P$ wave exists around a depth of $50 \mathrm{~km}$ beneath the volcanic front in Hokkaido. Moreover, there is another lowvelocity anomaly in the mantle wedge in the fore-arc region of Hokkaido. Since the resolution is good in the fore-arc region, the anomaly does not seem to be an artifact. This observation may indicate a dehydration process in the forearc region that is different from that of Tohoku.

We applied the tomographic method developed by Zhao 
et al. (1992) to arrival time data from shallow- and intermediate-depth local earthquakes in order to determine the detailed velocity structures of the $P$ and $S$ waves. The resolution is rather good in the mantle wedge for imaging large-scale deep structures. Future studies should be aimed at imaging small-scale heterogeneities shallower than 20 $\mathrm{km}$ with higher resolution in order to gain an understanding of the loading process of the tectonic stress. For this purpose a method for simultaneous velocity and density inversion appears to be valuable. (see Onizawa et al., 2002).

Acknowledgments. We thank C. Frohlich, an anonymous referee, and K. Yomogida for useful comments. We also thank D. Zhao at Ehime University and T. Urabe at the Earthquake Research Institute, University of Tokyo for providing computer softwares for a 3D seismic tomography and a data acquisition system, respectively. J. Nakajima at Tohoku University provided us with the results obtained by Nakajima et al. (2001). We used waveform data from stationary seismic stations maintained by Hokkaido University, Hirosaki University, Tohoku University, Sapporo City, JMA and NIED. This research forms a part of "The new Program of the Study and Observation for Earthquake Prediction" in Japan (Hirata, 2000). GMT-SYSTEM (Wessel and Smith, 1991) was used to make figures.

\section{References}

Arita, K., T. Ikawa, T. Ito, A. Yamamoto, M. Saito, Y. Nishida, H. Satoh, G. Kimura, T. Watanabe, T. Ikawa, and T. Kuroda, Crustal structure and tectonic of the Hidaka Collision Zone, Hokkaido (Japan), revealed by vibroseis seismic reflection and gravity surveys, Tectonophysics, 290, 197-210, 1998.

DeMets, C., Oblique convergence and deformation along the Kuril and Japan trenches, J. Geophys. Res., 97, 17615-17625, 1992.

DeMets, C., R. G. Gordon, D. F. Argus, and S. Stein, Effect of recent revisions to the geomagnetic reversal time scale on estimation of current plate motions, Geophys. Res. Lett., 21, 2191-2194, 1994.

Hirata, N., Panel on Earthquake Research, paper presented at the Third Joint Meeting, U.S.-Japan Natural Resources, Menlo Park, California, USA, November 13 to $15,2000$.

Katsumata, K., N. Wada, and M. Kasahara, Newly imaged shape of the deep seismic zone within the subducting Pacific plate beneath the Hokkaido corner, Japan-Kurile arc-arc junction, J. Geophys. Res., 108(B12), 2565, 2003.

Kimura, G., Collision orogeny at arc-arc junctions in the Japanese Islands, The Island Arc, 5, 262-275, 1996.

Miyamachi, H. and T. Moriya, Velocity structure beneath the Hidaka Mountains in Hokkaido, Japan, J. Phys. Earth, 32, 13-42, 1984.

Miyamachi, H., M. Kasahara, S. Suzuki, K. Tanaka, and A. Hasegawa, Seismic velocity structure in the crust and upper mantle beneath northern Japan, J. Phys. Earth, 42, 269-301, 1994.
Murai, Y., S. Akiyama, K. Katsumata, T. Takanami, T. Yamashina, T. Watanabe, I. Cho, M. Tanaka, A. Kuwano, N. Wada, H. Shimamura, I. Furuya, D. Zhao, and R. Sanda, Delamination structure imaged in the source area of the 1982 Urakawa-oki earthquake, Geophys. Res. Lett., 30, 43-1-4, 2003.

Nakajima, J., T. Matsuzawa, A. Hasegawa, and D. Zhao, Three dimensional structures of $V_{p}, V_{s}$, and $V_{p} / V_{s}$ beneath the northeastern Japan arc: implications for arc magmatism and fluids, J. Geophys. Res., 106, 21843-21857, 2001.

Nakajima, J. Y. Takei, and A. Hasegawa, Quantitative analysis of the inclined low velocity zone in the mantle wedge of northeastern Japan: A systematic change of melt-filled pore shapes with depth and its implications for melt migration, Earth Planet Sci. Lett., 234, 59-70, 2005.

Ogiso, M, K. Yomogida, and K. Katsumata, Recursive travel-time inversion: A tool for real-time seismic tomography, Earth Planets Space, 57, 477-489, 2005.

Onizawa, S., H. Mikada, H. Watanabe, and S. Sakashita, A method for simultaneous velocity and density inversion and its application to exploration of subsurface structure beneath Izu-Oshima volcano, Japan, Earth Planets Space, 54, 803-817, 2002.

Research Group for Explosion Seismology, Seismic refraction/wide-angle reflection experiment across the Hidaka Collision Zone, Hokkaido (Ohtaki-Urahoro profile), Bull. Earthq. Res. Inst. Univ. Tokyo, 77, 139172, 2002 (in Japanese).

Takahashi, H., M. Kasahara, F. Kimata, S. Miura, K. Heki, T. Seno, T. Kato, . Vasilenko, A. Ivashchenko, V. Bahtiarov, V. Levin, E. Gordeev, F. Korchagin, and M. Gerasimenko, Velocity field of around the Sea of Okhotsk and Sea of Japan regions determined from a new continuous GPS network data, Geophys. Res. Lett., 26, 2533-2536, 1999.

Takanami, T., Three-dimensional seismic structure of the crust and upper mantle beneath the orogenic belts in southern Hokkaido, Japan, J. Phys. Earth, 30, 87-104, 1982.

Tsumura, N., H. Ikawa, T. Ikawa, M. Shinohara, T. Ito, K. Arita, T. Moriya, G. Kimura, and T. Ikawa, Delamination-weage structure beneath the Hidaka Collision Zone, Central Hokkaido, Japan inferred from seismic reflection profiling, Geophys. Res. Lett., 26, 1057-1060, 1999.

Wessel, P. and W. H. F. Smith, Free software helps map and display data, Eos Trans. AGU, 72, 445-446, 1991.

Zhao, D., A tomographic study of seismic velocity structure in the Japan Islands, Ph. D. thesis, 301 pp., Tohoku Univ., Sendai, Japan, 1991.

Zhao, D. and A. Hasegawa, P wave tomographic imaging of the Crust and upper Mantle beneath the Japan Islands, J. Geophys. Res., 98, 43334353, 1993.

Zhao, D., S. Horiuchi, and A. Hasegawa, 3-D seismic velocity structure of the crust and the uppermost mantle in the northeastern Japan arc, Tectonophysics, 181, 135-149, 1990.

Zhao, D., A. Hasegawa, and S. Horiuchi, Tomographic imaging of P and $\mathrm{S}$ wave velocity structure beneath northeastern Japan, J. Geophys. Res., 97, 19909-19928, 1992.

K. Katsumata (e-mail: kkatsu@mail.sci.hokudai.ac.jp), N. Wada, and M. Kasahara 